\title{
Educação profissional no Brasil: motivos socioeconômicos e ideológicos da política educacional
}

\author{
ROBERTO ANTONIO DEITOS \\ Universidade Estadual do Oeste do Paraná, \\ Cascavel, PR, Brasil \\ ANGELA MARA DE BARROS LARA \\ Universidade Estadual de Maringá, \\ Maringá, PR, Brasil
}

\section{RESUMO}

Neste artigo analisamos os aspectos socioeconômicos e ideológicos da política educacional nacional para a educação profissional no Brasil em período recente (2003-2013). Buscamos compreender as justificativas e os argumentos sustentadores das proposições governamentais apresentadas para a implementação e a operacionalização das ações e programas para as políticas públicas de educação profissional. Assim, examinamos alguns aspectos dessas justificativas e argumentos socioeconômicos e ideológicos que consideram a existência de deficiências formativas da força de trabalho e que, desse modo, estariam produzindo insuficientes condições operacionais e funcionais para atender a demandas dos setores produtivos e, consequentemente, elevar a escolarização, a qualificação e a renda salarial no país.

\section{PALAVRAS-CHAVE}

políticas educacionais; educação profissional; escolarização e força de trabalho. 


\title{
PROFESSIONAL EDUCATION IN BRAZIL: SOCIOECONOMIC AND IDEOLOGICAL REASONS OF EDUCATIONAL POLICY
}

\begin{abstract}
In this paper we analyze the socioeconomic and ideological aspects of the national education policy for professional education in Brazil in the recent period (2003-2013). We seek to understand the justifications and arguments of government proposals submitted for the implementation and operationalization of activities and programs for public policies in professional education. Thus, we examine some aspects of these socioeconomic and ideological justifications and arguments that consider the existence of formative deficiencies in the workforce thereby producing insufficient operational and functional conditions to meet the demands of productive sectors and, consequently, raise the schooling, qualification and salary income in the country.
\end{abstract}

KEYWORDS

educational policies; professional education; schooling and workforce.

\section{EDUCACIÓN PROFESIONAL EN BRASIL: MOTIVOS SOCIOECONÓMICOS E IDEOLÓGICOS DE LA POLITTICA EDUCACIONAL}

\section{RESUMEN}

En este trabajo analizamos los aspectos socioeconómicos e ideológicos de la política educacional nacional para la educación profesional en Brasil en periodo reciente (2003-2013). Buscamos comprender las justificativas y los argumentos que sostienen las proposiciones gubernamentales presentadas para la implementación de las acciones y programas para las políticas públicas de educación profesional. Para tal, verificamos algunos aspectos de estas justificativas y argumentos socioeconómicos e ideológicos que consideran la existencia de deficiencias formativas de la fuerza del trabajo y que, de esa manera, estarían produciendo insuficientes condiciones operacionales y funcionales para atender las demandas de los sectores productivos y, consecuentemente, elevar la escolarización, la cualificación y la renta del sueldo en el país.

\section{PALABRAS CLAVE}

políticas educacionales; educación profesional; escolarización y fuerza de trabajo. 


\section{INTRODUÇÃO}

Os parâmetros de sustentabilidade e racionalidade política apresentados para a política educacional brasileira, diante dos problemas educacionais, têm como justificativas socioeconômicas e ideológicas a necessidade de educação profissional, tendo em vista a deficiência formativa da força de trabalho. Ao mesmo tempo, essa força de trabalho é obrigada pelas circunstâncias históricas a possuir determinadas exigências profissionais que o processo produtivo demanda. Em certa medida e, muitas vezes, de maneira parcial e relativa, certos requisitos são exigidos permanentemente no processo de produção e reprodução do capital (Aquino, 2009; Banco Mundial, 1997, 2009; Brasil, 1996, 2007a, 2007b, 2008, 2009, 2010a, 2010b, 2011a, 2011b, 2012a, 2012b; Bryan, 2008; Deitos, 2000, 2003, 2005, 2006; Marx, 1983).

Neste artigo, ${ }^{1}$ analisamos os aspectos socioeconômicos e ideológicos da política educacional nacional para a educação profissional no Brasil no período recente: 2003-2013. Buscamos compreender as justificativas e os argumentos sustentadores das proposições governamentais apresentadas para a realização e operacionalização de ações e programas para as políticas públicas de educação profissional. Examinamos alguns aspectos dessas justificativas e argumentos socioeconômicos e ideológicos que consideram a existência de deficiências formativas da força de trabalho, que estariam produzindo insuficientes condições operacionais e funcionais para atender às demandas dos setores produtivos e, consequentemente, a necessidade de elevar a escolarização, a qualificação e a renda salarial no país.

$\mathrm{O}$ artigo está organizado da seguinte maneira: na primeira parte tratamos dos argumentos e das justificativas ideológicas para a política de educação profissional; na segunda parte apresentamos a análise dos argumentos socioeconômicos e a funcionalidade da política de educação profissional na regulação da força de trabalho no Brasil; em seguida apresentamos as considerações finais.

\section{ARGUMENTOS E JUSTIFICATIVAS IDEOLÓGICAS PARA A POLÍTICA DE EDUCAÇÃO PROFISSIONAL}

Um primeiro aspecto apresentado refere-se à argumentação de que a reforma da política educacional, desenvolvida em âmbito nacional, envolvendo particularmente a política de educação profissional, está relacionada diretamente com o processo de flexibilização das relações de trabalho no Brasil.Justifica-se que essa reforma

1 Temática revista e ampliada do originalmente constituinte do relatório de pesquisa Estado e política pública de educação profissional: os motivos socioeconômicos e politicos e as razóes educacionais e teórico-ideológicas da política educacional paranaense, vinculado ao estágio de pós-doutorado no Programa de Pós-Graduação em Educação e do Grupo de Estudos e Pesquisa em Estado, Políticas Educacionais e Infância (GEPPEIN) da Universidade Estadual de Maringá (UEM) e ao Grupo de Estudos e Pesquisas em Política Educacional e Social (GEPPES) da Universidade Estadual do Oeste do Paraná (UNIOESTE), com apoio e financiamento da Fundação Araucária, Secretaria da Ciência, Tecnologia e Ensino Superior do Paraná (SETI) e do Governo do Paraná, concluído em março de 2013. 
seria necessária para atender às novas exigências e às competências produtivas e tecnológicas demandadas pela modernização e competitividade das empresas e da economia brasileira à sua integração ao mercado globalizado, impulsionada pelo chamado novo desenvolvimentismo (Bresser-Pereira, 2011; Mercadante-Oliva, 2010). O segundo aspecto apresentado trata da justificativa ideológica generalizada que revela as condições para relativizar e escamotear os condicionantes funcionais da educação. No quadro da crise estrutural do capitalismo, a questão de fundo que move a situação da força de trabalho consiste, segundo István Mészáros (2002, p. 1.005, grifos do original), no seguinte:

[...] o problema não se restringe à difícil situação dos trabalhadores não qualificados, mas atinge também um grande número de trabalhadores altamente qualificados, que agora disputam, somando-se ao estoque anterior de desempregados, os escassos - e cada vez mais raros - empregos disponíveis. Da mesma forma, a tendência da amputação "racionalizadora" não está mais limitada aos "ramos periféricos de uma indústria obsoleta", mas abarca alguns dos mais desenvolvidos e modernizados setores da produção - da indústria naval e aeronáutica à eletrônica, e da indústria mecânica à tecnologia espacial.

Portanto, não estamos mais diante dos subprodutos "normais" e voluntariamente aceitos do "crescimento e do desenvolvimento", mas de seu movimento em direção a um colapso; nem tampouco diante de problemas periféricos dos "bolsões de subdesenvolvimento"!, mas diante de uma contradição fundamental do modo de produção capitalista como um todo, que transforma até mesmo as últimas conquistas do "desenvolvimento", da "racionalização" e da "modernização" em fardos paralisantes de subdesenvolvimento crônico. E o mais importante de tudo é que quem sofre todas as consequências dessa situação não é mais a multidão socialmente impotente, apática e fragmentada das pessoas "desprivilegiadas", mas todas as categorias de trabalhadores qualificados e não qualificados: ou seja, obviamente, a totalidade da força de trabalho da sociedade.

Ao considerarmos os dois aspectos apresentados, compreendemos que a política educacional fica tencionada a atender às necessidades exigidas pela maioria da população trabalhadora e, ao mesmo tempo, procura responder às exigências que o processo de produção capitalista estabelece como requisitos técnicos, formativos e ideológicos, requeridos à composição da força de trabalho necessária e do estoque disponível para os setores econômicos nacionais e transnacionais.

Nesse contexto, é que o discurso oficial sobre a implementação de políticas educacionais e de profissionalização da força de trabalho nacional, contraditoriamente, subordina o processo de escolarização e a formação profissional aos interesses hegemônicos econômicos e políticos vigentes. Com um discurso político definido, o Ministro da Educação afirma em entrevista:

[...] Educação, Ciência e Tecnologia e Inovação entram como eixos estruturantes para que a gente pense a crise para além da conjuntura. Para ganhar competitividade, o Brasil precisa aprender a fazer mais e melhor porque a crise exige 
mais educação. Esse é o diferencial em relação aos países que estão adotando um regime ortodoxo, com desemprego, arrocho de salários, cortes na demanda agregada. Nós estamos mantendo a demanda agregada, estimulando o investimento, mas nós precisamos ganhar competitividade, e a educação é um elemento fundamental. (Mercadante, 2012, p. 4)

A definição de medidas que determinam a estrutura da educação e da formação profissional no contexto da política educacional realizada no país e regionalmente configurada nas unidades federativas não foge aos requisitos socioeconômicos elencados pelo processo produtivo e pelos seus gestores, personificados nas lideranças empresariais corporificadas em sujeitos e instituições socioempresariais, localizadas nos chamados ramos produtivos e econômicos do país, regiões ou localidades (ANPEd, 2011; FIEP, 2011, 2012).

Por isso,

Historicamente, em nosso país, as políticas educacionais não favoreceram que alunos das classes trabalhadoras realizassem um percurso educacional capaz de garantir o direito à conclusão da educação básica com formação integral [...]. Assim, ao longo dos anos, a desigualdade e a exclusão social foram se ampliando no Brasil, resultando daí grande contingente da população que vive em situação de pobreza, que não concluiu a trajetória escolar e nem possui formação profissional qualificada.

Esse processo histórico de produção de desigualdades sociais gestou um sistema educacional marcado pela inculcação ideológica e evasão escolar. Nesse sentido, a educação geral e profissional destinada aos trabalhadores caracteriza-se, desde as origens, pela insuficiência de recursos, terminalidade em níveis elementares da escolarização, configuração de currículos e modelos educacionais de adestramento para o trabalho, limitados ao mínimo necessário à funcionalidade requerida pelo movimento de acumulação do capital, delineando os contornos da dualidade estrutural [...]. (Shiroma; Lima Filho, 2011, p. 727-728)

Uma visão hegemônica de liderança socioeconômica e política de setores empresariais, configurada como representação da classe proprietária dos meios de produção e, desse modo, promotora de determinada visão social e ideológica sobre educação e formação profissional, supostamente necessária aos mecanismos de funcionamento da sociedade, produz políticas formativas capazes de atender aos seus interesses imediatos e, contraditoriamente, negar o atendimento coletivo das necessidades educativas e culturais para o conjunto da população.

A funcionalidade requerida pelos setores empresariais e pelas instituições orgânicas de gestão do capital acaba sendo a difusão de um diagnóstico da deficiência do próprio sistema educacional para atender aos requerimentos socioeconômicos modernizantes, ancorados no discurso do novo desenvolvimento, que graça nos círculos oficiais e econômicos hegemônicos, por isso alguns dos sujeitos institucionais consideram o seguinte: 
O Brasil tem ampliado a cobertura dos serviços de educação e criado sistemas de avaliação que constituem ferramentas eficazes de apoio para a gestão escolar. Não obstante, o país enfrenta problemas no setor, entre os quais se destacam os seguintes: (i) qualidade insuficiente da educação secundária; (ii) cobertura incompleta da educação na primeira infância (creches e pré-escolares - centros de educação infantil) e o ensino médio; e (iii) falta de habilidades cognoscitivas e não cognoscitivas e de capacitação dos jovens para o mercado de trabalho. (BID, 2012, p. 6-7, tradução nossa)

O diagnóstico da ineficiência educacional e da inadequada capacitação dos jovens para o mercado de trabalho tem sido historicamente ${ }^{2}$ um forte discurso de orientação para a realização de políticas educacionais, como o apresentado pelo Banco Interamericano de Desenvolvimento (BID):

Superar tais problemas é também um objetivo central do Plano de Desenvolvimento da Educação e está respaldado nas diretrizes do Plano Nacional de Educação 2011-2020. O Banco apoiará fundamentalmente os estados e municípios, sem excluir a União e o setor privado, em esforços dirigidos a (i) melhorar a qualidade da educação básica, por meio da formação e capacitação de professores e aperfeiçoamento e maior utilização dos instrumentos de avaliação disponíveis; (ii) expandir a cobertura da educação escolar infantil e ensino médio através da reforma das instituições de ensino, a aquisição e preparação de material didático e qualificação do corpo docente, incentivando a permanência e conclusão desta capacitação; e (iii) assegurar as habilidades necessárias para melhorar as possibilidades de emprego dos jovens, sobre todo o ensino médio (regular e de profissionalização), ao que se agregam iniciativas na esfera do ensino técnico por meio de parcerias público-privadas, promoção de mudanças privadas vinculadas a um maior acesso ao mercado de trabalho e apoio a programas de esportes para jovens nas 12 cidades-sede da Copa do Mundo de Futebol 2014. (idem, p. 7, tradução nossa)

Desse modo, o receituário proposto sempre segue a linha da caracterização da ineficiência e da positividade das reformas educativas para superá-las.

\section{ARGUMENTOS SOCIOECONÔMICOS E A FUNCIONALIDADE DA POLÍTICA DE EDUCAÇÃO PROFISSIONAL NA REGULAÇÃO DA FORÇA DE TRABALHO}

A funcionalidade da política educacional na regulação de medidas operacionais e sociais para a formação do estoque (qualitativo/quantitativo) da força de

2 Entre outros, destacamos: Banco Mundial (1992, 2010b), Castro et al. (2000) e Xavier (1990). 
trabalho no Brasil, com habilidades mínimas suficientes para os requerimentos produtivos e necessária para o equilíbrio das vantagens competitivas do capital, é a marca predominante na definição dos objetivos nacionais, regionais e locais para a consumação de processos educativos e formativos realizados no país e nas unidades federativas que o constituem nacionalmente. Nessa mesma composição da funcionalidade que a política educacional integra, há o fator ideológico da necessidade educativa e socialmente necessária que a população exige como condição social própria à sobrevivência cultural e social dos trabalhadores.

A educação, portanto, constitui parte da estrutura social dominante, na medida em que fornece os elementos básicos necessários ao processo produtivo e também os requerimentos ideológicos para a funcionalidade socioeconômica da sociedade, mantendo as condições produtivas, a viabilidade política da ordem social e a regulação relativa da composição geradora de escolarização e profissionalização da força de trabalho (Deitos, 2010; Deitos et al., 2012; Xavier; Deitos, 2006; Zanardini, 2008).

O mais recente e audacioso programa que integra a política de educação profissional é o Programa Nacional de Acesso ao Ensino Técnico e Emprego (PRONATEC), criado em 2011 pelo governo federal (Brasil, 2011c, 2012b, 2012c, 2012d) e disseminado nacionalmente como âncora do processo de formação da força de trabalho no país. O programa estabelece os ajustes educativos, tecnológicos e profissionalizantes para os mecanismos formativos que as políticas educacionais nacional e regional devem adotar, integrar e articular para atender aos requerimentos demandados pelos setores produtivos entrelaçados no processo de transnacionalização das bases produtivas (Deitos, 2012). Como objetivos principais, o PRONATEC estabelece o seguinte:

I - expandir, interiorizar e democratizar a oferta de cursos de educação profissional técnica de nível médio presencial e a distância e de cursos e programas de formação inicial e continuada ou qualificação profissional;

II - fomentar e apoiar a expansão da rede física de atendimento da educação profissional e tecnológica;

III - contribuir para a melhoria da qualidade do ensino médio público, por meio da articulação com a educação profissional;

IV - ampliar as oportunidades educacionais dos trabalhadores, por meio do incremento da formação e qualificação profissional;

$\mathrm{V}$ - estimular a difusão de recursos pedagógicos para apoiar a oferta de cursos de educação profissional e tecnológica. (Brasil, 2011c, p. 1)

O grande eixo integrador do PRONATEC não está na negação aos outros objetivos e programas educativos e formativos estabelecidos pela política educacional nacional e regional ${ }^{3}$ (estados/municípios), mas na garantia da articulação e

3 Conferindo dados constantes em Brasil (2012b), podemos constatar os eixos principais normativos das proposições governamentais: "1) Objetivo Setorial: Ampliar a oferta 
adoção de mecanismos de funcionalidade aos requerimentos dos setores produtivos instalados que compõem a formação social e econômica brasileira, como podemos constatar em análises oficiais de instituições estatais, como o Instituto de Pesquisa Econômica Aplicada (IPEA):

Embora ainda não exista uma estimativa dos valores que deverão ser alocados ao Pronatec, este programa deverá ser o principal instrumento de financiamento da expansão da educação técnica e profissional do país no quadriênio 2012-2015. Além da expansão da rede federal, o Pronatec também financiará: a expansão das redes estaduais de educação profissional; a ampliação de vagas e a expansão da rede física de atendimento dos serviços nacionais de aprendizagem; e o acesso de estudantes e de trabalhadores a cursos técnicos, tecnológicos e de formação inicial e continuada. As metas divulgadas para a educação em nível técnico revelam o quão ambicioso é o Pronatec: busca-se alcançar, até 2014, a marca de 5 milhões de matrículas em cursos técnicos (integrados, concomitantes ou subsequentes ao ensino médio). Para se ter uma ideia do tamanho deste desafio, em 2010, o número de matrículas nessa modalidade chegou a 1,1 milhão. Por sua vez, o potencial de expansão é considerável: cerca de 8 milhões de jovens cursavam o ensino médio em 2010.

[...] São objetivos deste programa a expansão, interiorização e democratização da oferta de cursos técnicos e profissionais de nível médio, bem como de cursos de formação inicial e continuada para trabalhadores. (Brasil, 2012b, p. 121)

A funcionalidade que ocupa a política educacional na composição da força de trabalho e no ordenamento ideológico de condições sociais e psicopolíticas necessárias à estabilidade socioeconômica é destacável e visível em todas as orientações ou análises e recomendações nacionais ou internacionais, como as do presidente do BID:

Sem dúvida, a educação é uma das principais lutas para poder superar o atraso social da América Latina e Caribe. Poucos esforços em matéria de política pública têm uma recompensa tão grande como a de capacitar as gerações mais jovens e dar-lhes as ferramentas para se desempenhar no mercado de trabalho e aproveitar as oportunidades que oferece uma economia mais moderna e diversa, num cenário de crescente globalização. (Moreno, 2011, p. 46, tradução nossa)

Determinadas recomendações e diagnósticos apontam na mesma direção das variáveis formativas de competências requeridas e das deficiências educativas

da educação profissional levando em conta sua articulação com os demais níveis e modalidades de ensino. [...]; I - Programa Desenvolvimento da Educação Profissional e Tecnológica [...]; Resultados das principais ações realizadas no período 2008 a 2011: Acordo Sistema 'S' [...]; Expansão da Rede Federal de Educação Profissional e Tecnológica: - Programa Brasil Profissionalizado [...]; Programa Mulheres Mil [...]; Sistema Nacional de Informações da Educação Profissional e Tecnológica (SISTEC) [...]”. 
socialmente elencadas pelos setores produtivos e pelo cenário globalizante quando se referem à força de trabalho necessária e excedente para a manutenção e reprodução do processo produtivo capitalista.

[...] na maioria dos países da região, a estrutura tradicional, o currículo e o enfoque da educação média são obsoletos. Não se conta com uma educação acadêmica sólida, que seja compatível com as necessidades da sociedade moderna nem se está preparando adequadamente a todos os estudantes para o ingresso no mercado de trabalho. O número de disciplinas é excessivo, o que torna difícil aprofundar-se nelas e desenvolver habilidades.

Os cursos técnicos em geral estão sendo transferidos para o nivel pós-médio. Essa solução resolve pelo menos o problema crônico das escolas de ensino médio que se acham divididas entre a preparação para a educação superior e a formação profissional. Essa dicotomia faz com que, muitas vezes, as instituições não sejam capazes de executar bem nenhuma dessas funções. (Castro et al., 2000, p. 25-27, grifos do original, tradução nossa)

O receituário carrega dois elementos fundamentais ao recomendar as reformas educacionais na direção desejada pelos setores econômicos hegemônicos. Um é a crítica ardilosa afirmando que os conteúdos curriculares são obsoletos, e o outro é a necessidade de preparação visando desenvolver habilidades para os estudantes ingressarem no mercado de trabalho. Nesses dois elementos centrais é que os projetos e reformas educativas e formativas da juventude e da força de trabalho são dirigidos e financiados pelas agências internacionais:

Perto da quarta parte dos projetos novos se concentra no ensino médio e na formação profissional, com intervenções para ajudar a assegurar que a educação permita o desenvolvimento das atitudes necessárias para satisfazer a demanda do mercado de trabalho. (Banco Mundial, 2010a, p. 16, tradução nossa)

As agências nacionais ligadas à estrutura estatal ou à estrutura de organização sindical e social também não fogem de certos ingredientes do mesmo receituário e admitem parcialmente alguns diagnósticos e medidas. Entretanto, realizam uma crítica a determinados aspectos do discurso hegemônico do empresariado nacional, em especial ao discurso da escassez relativa de trabalhadores qualificados, como podemos observar a seguir nos apontamentos do Departamento Intersindical de Estatística e Estudos Socioeconômicos (DIEESE):

Nos últimos anos, o ambiente de crescimento persistente da produção brasileira e a forte dinâmica de criação de novos postos de trabalho geraram a sensação de escassez relativa de trabalhadores qualificados no mercado de trabalho. Essa percepção, inicialmente formulada pelo meio empresarial, foi rapidamente absorvida pela mídia e refletida nos meios de comunicação na forma de um "apagão de mão de obra". [...]. Tal informação torna-se relevante para que se entenda que o Brasil não enfrenta um "apagão de mão de obra" - no sentido de uma es- 
cassez generalizada de trabalhadores qualificados - mas apresenta, sim, maiores dificuldades no recrutamento de determinadas ocupações de setores da economia aquecidos com o crescimento brasileiro no período recente. (DIEESE, 2011, p. 7)

A crítica da entidade que presta assessoria aos sindicatos dos trabalhadores é coerente ao demonstrar que certas afirmações do receituário empresarial estão fortemente carregadas de sentido ideológico, na direção de pressões para exigir determinadas qualificações à formação da força de trabalho. Outra constatação é a de que o empresariado pressiona a estrutura estatal para o fornecimento e ampliação de políticas públicas que favoreçam essas medidas e possibilitem baixar os custos produtivos da força de trabalho em duas direções estratégicas: o custo da formação e qualificação dos trabalhadores e a ampliação do excedente de força de trabalho para baixar os salários médios na composição geral da massa salarial. $\mathrm{O}$ volume da população ativa e ocupada no Brasil ( $80 \%$ com até 49 anos de idade, dados de 2011) é uma demonstração do estoque geral da força de trabalho disponível, como podemos observar no Gráfico 1.

Gráfico 1 - Composição da população ocupada por faixa etária (\%)

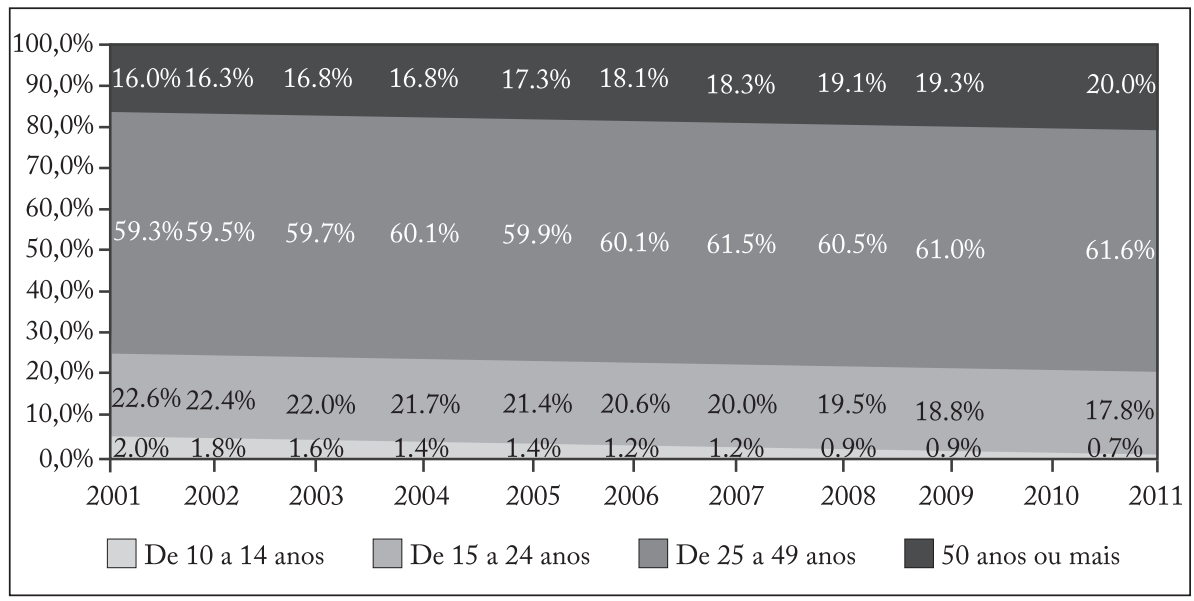

Fonte: PNAD 2011 (Brasil, 2012d, p. 14).

O Gráfico 1 é mais bem compreendido quando observamos a quantidade da população ativa e ocupada disponível no país, conforme dados da Pesquisa Nacional por Amostra de Domicílios (PNAD) 2011, ao verificarmos que a População em Idade Ativa (PIA) correspondia, em 2011, a 118,1 milhões de pessoas, mas a População Ocupada (PO) correspondia a 121 milhões de pessoas (Brasil, 2012b). Os dados sobre a distribuição nacional da ocupação por faixa etária, analisados à luz dos dados do Gráfico 2, fornecem uma dimensão perversa do quadro econômico e social brasileiro recente. 
Gráfico 2 - Taxa de ocupação por faixa etária (\%)

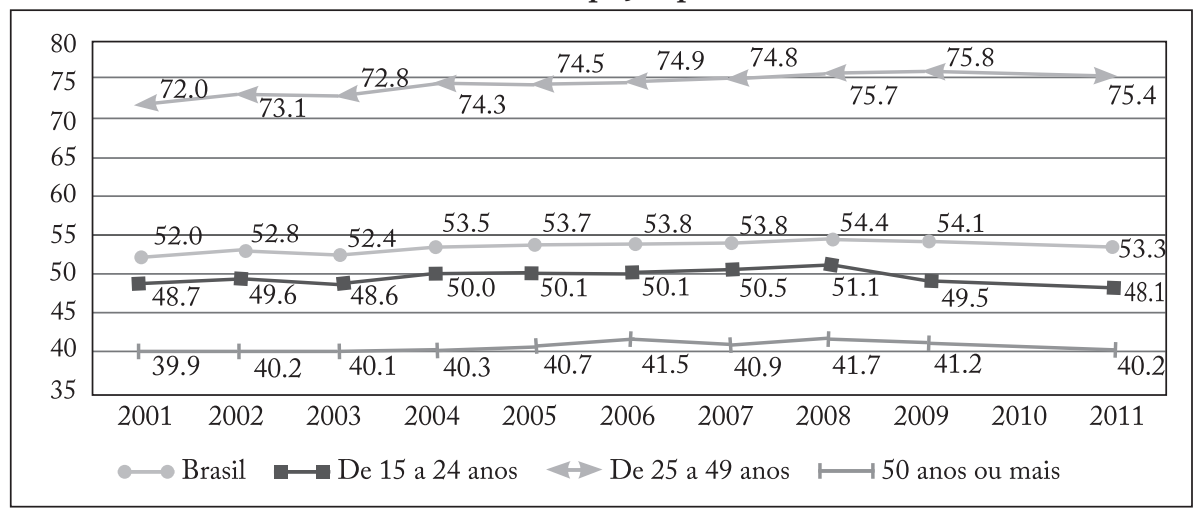

Fonte: PNAD 2011 (Brasil, 2012d, p. 13).

Os dados apresentados no Gráfico 2 nos possibilitam visualizar a dimensão que toma a ocupação dos jovens e adultos trabalhadores no quadro social brasileiro. Esses dados demonstram alguns aspectos que merecem nossa atenção. O primeiro é o de que pelo menos $25 \%$ da população entre 25 e 49 anos não detinham nenhum tipo de ocupação. O outro aspecto refere-se ao fato de que a população juvenil de 15 a 24 anos sem ocupação correspondia a $51 \%$ do universo de pessoas nessa faixa etária. Um terceiro aspecto refere-se aos adultos com idade acima de 50 anos que não possuíam nenhuma ocupação, segmento populacional que atingia quase $60 \%$ do universo de pessoas nessa faixa etária.

Se relacionarmos os dados anteriores aos obtidos no Censo de 2010 do Instituto Brasileiro de Geografia e Estatística (Brasil, 2011b), verificamos que a população juvenil entre 15 e 24 anos correspondia a pouco mais de 34 milhões de pessoas e que, destas, pouco mais de 17 milhões não detinham nenhuma ocupação. Já a população entre 25 e 49 anos correspondia a pouco mais de 71 milhões de pessoas, e quase 18 milhões não detinham nenhum tipo de ocupação. Ou seja, a população entre 15 e 49 anos sem nenhum tipo de ocupação (formal ou informal) atingia 35 milhões de pessoas. Se verificarmos a população de 50 a 64 anos, que correspondia, aproximadamente, a 25 milhões de pessoas, e, destas, quase 15 milhões estavam sem ocupação alguma, somadas as 35 milhões de pessoas sem nenhuma ocupação na faixa etária de 15 a 49, teremos uma população de aproximadamente 50 milhões de pessoas sem nenhuma ocupação. Segundo os mesmos dados, da população que detinha alguma ocupação na faixa etária de 15 a 64 anos, 40\% estavam inseridas em ocupações sem carteira assinada, uma parte delas em ocupações desenvolvidas por conta própria e outra parte significativa em ocupações precárias e com grande vulnerabilidade socioeconômica.

Os dados de 2001 a 2011, apresentados pela PNAD 2011 (Brasil, 2012b), demonstram o volume da massa de trabalhadores ocupados no conjunto dos setores econômicos nacionais, distribuídos em ocupações formais, empregadores, atividades diversas por conta própria, atividades profissionais liberais e outras atividades con- 
sideradas mal definidas. Nesses dados, as ocupações nos setores agrícola, industrial e relativo a serviços tiveram quedas na distribuição de ocupações, o que se verifica também nas atividades relacionadas ao comércio, à construção, à administração pública e aos transportes. Já as consideradas como outras atividades apresentaram crescimento relativo e elevada precariedade laboral, mas foram as que tiveram maior crescimento na distribuição das ocupações.

Ao analisarmos a distribuição por grupos de escolaridade da força de trabalho ocupada, conforme o Gráfico 3, constatamos um relativo avanço na composição dos ocupados em relação aos níveis de escolaridade nos grupos com mais de onze anos de estudos absorvendo 50\%, e com quatro a dez anos de estudos, $35 \%$. A força de trabalho ocupada com zero a três anos de estudos, em 2011, absorvia $15 \%$ do total da população ocupada.

Gráfico 3 - Total de ocupados e distribuição por grupos de escolaridade

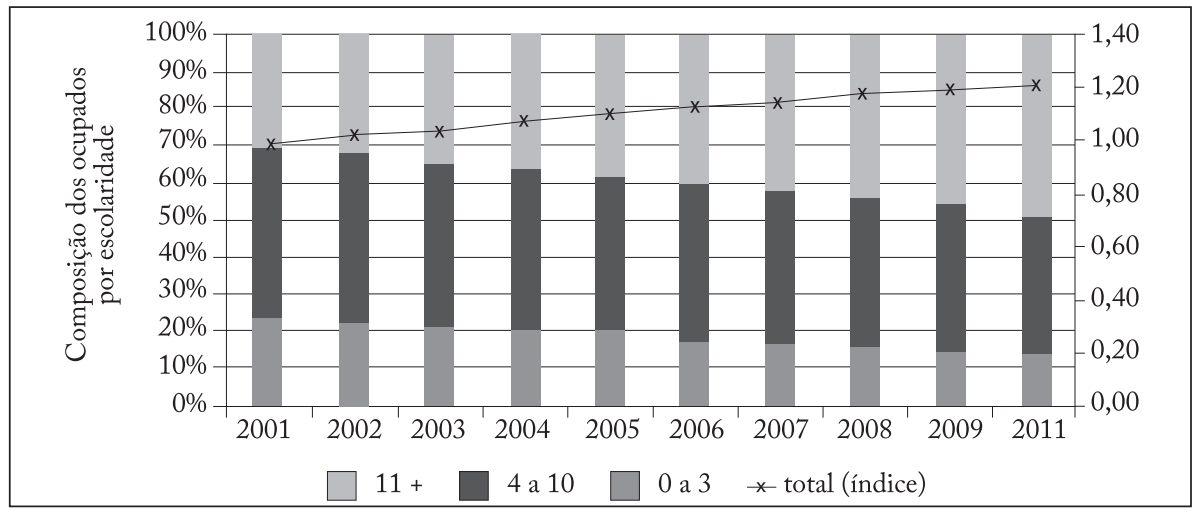

Fonte: PNAD 2011 (Brasil, 2012d, p. 19).

O relativo aumento nos anos de estudo da população ocupada no país, de acordo com os dados de 2011 ( $\mathrm{idem}$ ), expressos nos índices de escolaridade da força de trabalho, são baixos se considerarmos a distribuição de ocupados na faixa com mais de onze anos de estudo, pois essa faixa de distribuição congrega os níveis de escolaridade final do ensino médio, e, acima de onze anos de escolaridade, o nível de ensino superior. De acordo com o diagnóstico do BID, uma justificativa para essa situação na América Latina e Caribe é a seguinte:

Ainda que os jovens que já completaram os estudos secundários constituam a proporção maior da nova força de trabalho da América Latina e do Caribe, o saldo relativo que se obtém está diminuindo, marcadamente por dois motivos: o aumento da oferta de trabalhadores com educação secundária, e as mudanças da demanda de pessoal formado que favorecem os trabalhadores com educação superior. (BID, s.d., p. 20, tradução nossa) 
Se a escolaridade em nível médio e superior tem tido relativo crescimento, a justificativa termina recaindo sempre na distribuição relacionada às mudanças na necessidade de força de trabalho com requisitos de educação superior. A pressão sobre a formação profissional da força de trabalho acaba por condicioná-la no sentido da profissionalização de nível médio e mais ainda para a de nível superior, em razão dos requisitos escolares e profissionalizantes exigidos pelos setores produtivos tanto da força de trabalho ocupada quanto da disponível. Isso gera um aumento da tensão sobre a massa da força de trabalho não qualificada e a considerada qualificada. Ainda mais, gera uma pressão interna na composição do volume dessa população de trabalhadores bem como na composição da massa salarial média, na busca de relativa queda da oferta salarial média por parte dos setores produtivos. Os requisitos por maiores níveis de escolaridade e qualificação profissional permitem esse processo de regulação da força de trabalho ocupada e disponível, correspondendo às exigências do processo de produção social e econômica.

Contraditoriamente, o processo de produção requer níveis de qualificação por ocupação que, de forma relativa, movem-se em desencontro com os níveis de escolarização (Brasil, 2012b, p. 19) requeridos pelos setores econômicos, como podemos verificar nos dados apresentados no Gráfico 4.

\section{Gráfico 4 - Distribuição por nível de qualificação exigido pela ocupação}

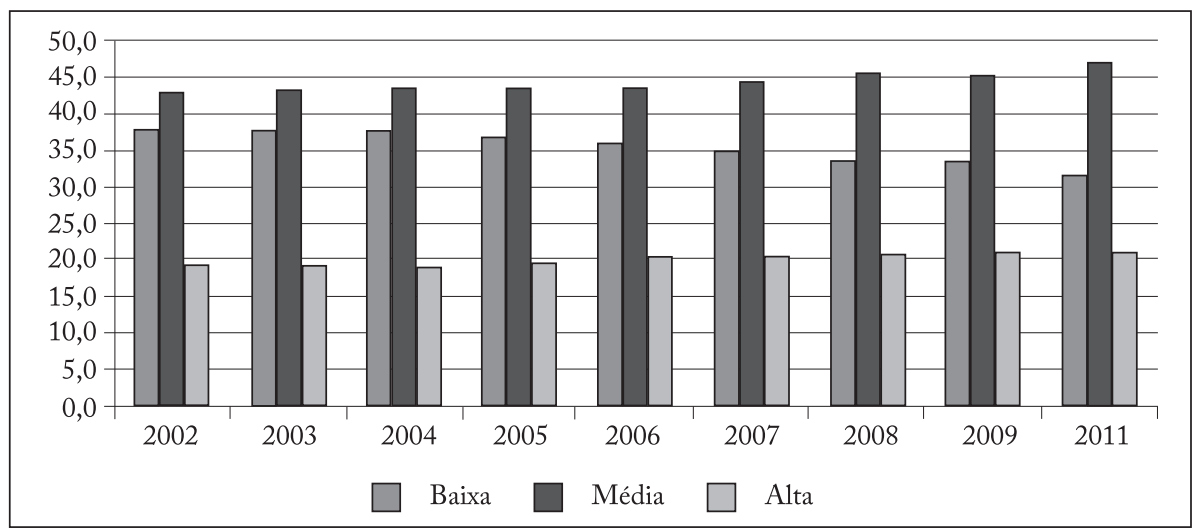

Fonte: PNAD 2011 (Brasil, 2012d, p. 22). ${ }^{4}$

4 Nota do original (nota 6, p. 21): David H. Autor, U.S. Labor Market Challenges over the Longer Term. Federal Reserve Board of Governors. Consultant Paper, October 2010. "Foram classificados como altamente qualificados os dirigentes, profissionais das ciências e das artes e técnicos de nível médio. No grupo de qualificação média foram incluídos os trabalhadores de serviços administrativos (escriturários e de atendimento), os vendedores e os trabalhadores da produção. Como pouco qualificados foram classificados os trabalhadores dos serviços (domésticos, de transportes, segurança, administração de edifícios, saúde, embelezamento, entre outros) e os agrícolas". 
Os dados do Gráfico 4 (idem) revelam que a distribuição de ocupação por nível de qualificação alta subiu apenas dois pontos percentuais de 2002 a 2011. Já a distribuição da ocupação por nível de qualificação média cresceu em torno de quatro pontos percentuais no mesmo período, o que também não é muito elevado. E, por fim, a distribuição de ocupação por nível de qualificação baixa caiu seis pontos percentuais no mesmo período. Apesar do aumento relativo dos anos de estudo dos trabalhadores nos últimos dez anos, constatamos que o aumento da escolarização não é o principal item com relação à exigência para as ocupações, mas requisito para o processo de pressão e seleção da quantidade de força de trabalho necessária, tanto que $79 \%$ da distribuição por nível de qualificação, exigidos pela ocupação, estão centrados nos níveis de baixa e média qualificação.

A política nacional de educação profissional estabelece o conjunto de eixos tecnológicos dos cursos técnicos no Catálogo Nacional de Cursos que abrange todos os setores produtivos e econômicos: 1) ambiente e saúde, com 29 cursos; 2) controle e processos industriais, com 25 cursos; 3 ) desenvolvimento educacional e social, com 11 cursos; 4) gestão e negócios, com 17 cursos; 5) informação e comunicação, com 9 cursos; 6) infraestrutura, com 17 cursos; 7) militar, com 34 cursos; 8) produção alimentícia, com 8 cursos; 9) produção cultural e design, com 29 cursos; 10) produção industrial, com 18 cursos; 11) recursos naturais, com 15 cursos; 12) segurança, com 2 cursos; 13) turismo, hospitalidade e lazer, com 7 cursos (Brasil, 2012a).

Os dados do Gráfico 5, referentes ao censo escolar das matrículas efetivas de 2007 a 2010, já revelavam um crescimento significativo no volume de matrículas da educação profissional nas redes públicas estadual e federal e, principalmente, na rede privada.

\section{Gráfico 5 - Número de matrículas na educação profissional por dependência administrativa (Brasil 2007-2010)}

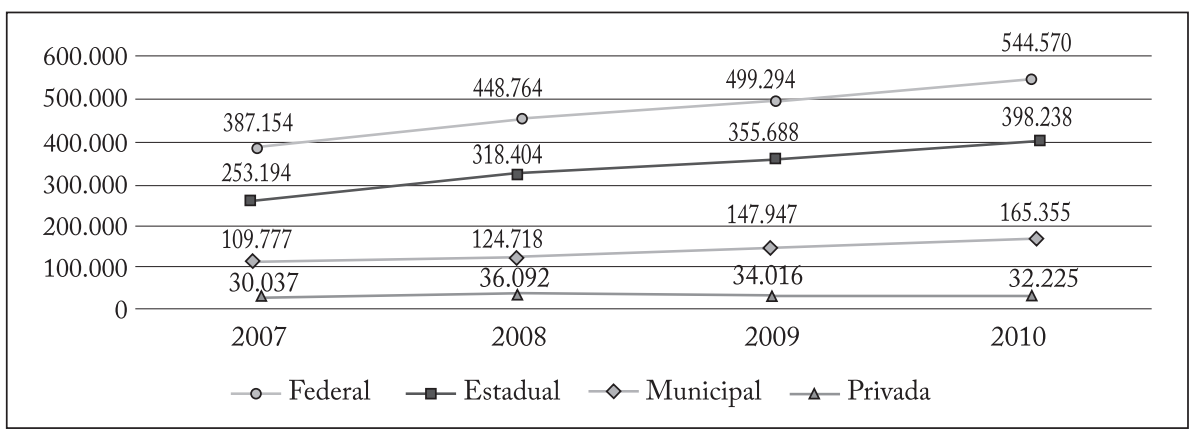

Fonte: Brasil (2011a, p. 25).

Os dados apresentados revelam a expansão da educação profissional, com maior volume de matrículas, seja nos dados do Censo Escolar de 2010 ou nos dados do SISTEC (Brasil, 2012f), na esfera das instituições privadas de ensino, com volume bastante elevado em relação ao apresentado pelas redes públicas estadual e federal. 
Dados do Censo Escolar de 2010 (Brasil, 2011a) também apresentam a distribuição do número de matrículas da educação profissional e o volume maior da oferta em cursos subsequentes do ensino médio, concentrando $62,1 \%$ das matrículas. Já o ensino médio profissional concomitante e o integrado abarcavam, cada um, em torno de $19 \%$ das matrículas. Essa situação demonstra que a profissionalização para concluintes do ensino médio é mais expressiva. Outra questão é se, de fato, essa é uma prioridade. Quando, em uma política massiva de profissionalização, os índices de acesso e permanência no ensino médio regular ainda são baixos se considerarmos que aproximadamente apenas $50 \%$ da população juvenil brasileira frequenta o ensino médio regular em idade adequada.

\section{CONSIDERAÇÕES FINAIS}

A educação acaba sendo associada ideológica e economicamente ao processo de produção e à competitividade econômica. $\mathrm{O}$ campo em que sujeitos sociais vendem sua força de trabalho para subsistir determina as mediações sociais exigidas nos processos educativos e, em especial, os requisitos educativos e de formação profissional da força de trabalho demandada em circunstâncias produtivas e socioculturais necessárias ao processo produtivo, sob a égide da globalização do capital (Deitos, 2011). Tanto é assim que as recomendações governamentais explicitadas em discurso da presidente da República revelam que:

Sem especializados, nós não seremos e não realizaremos aquilo que podemos, todo nosso potencial. Porque é sabido isso, o mundo hoje está entrando num outro momento, a chamada economia do conhecimento. Quanto mais estudo, melhor para o país [...]. (Rousseff, 2013, s.p., grifos nossos)

Não por acaso, o Banco Mundial, em análises, recomendações e diagnósticos sobre a política educacional brasileira, fazia, em documento de 2010, vários apontamentos, alguns surpreendentes e muito reveladores, do quadro da educação, como podemos observar a seguir:

A ampliação gigantesca da escolaridade no Brasil durante os últimos 15 anos teve notáveis efeitos sobre a força de trabalho. Em 1993, aproximadamente 70 por cento da força de trabalho não havia completado o ensino médio. Hoje este número é de 40 por cento. A maior mudança não é o acesso ao ensino fundamental, mas sim a proporção muito maior de crianças que permanecem na escola até completar o ensino médio. $\mathrm{O}$ aumento na proporção de trabalhadores com ensino médio tem sido acompanhado de uma redução no salário real dos formandos do ensino médio nos últimos anos. Ao mesmo tempo, houve um aumento do diferencial de salários para os formandos do ensino superior, que é consistente com o crescimento global de demanda por trabalhadores com fortes habilidades analíticas. Os dados do mercado de trabalho no Brasil estão assinalando que as "habilidades do Século 21" são importantes para a próxima geração de trabalhadores no Brasil, e a produção destes será um desafio crítico para o sistema educacional na próxima década: formandos com a capacidade 
de pensar analiticamente, fazer perguntas críticas, aprender novas habilidades, e operar com alto nível de habilidades interpessoais e de comunicação, inclusive com o domínio de idiomas estrangeiros e a capacidade de trabalhar eficazmente em equipes. Para o sistema de educação básica, a implicação principal é a da urgência de aumentar a aprendizagem estudantil. (Banco Mundial, 2010b, p. 3)

Alguns aspectos da referida análise do Banco Mundial são destacáveis: o primeiro refere-se ao aumento da escolaridade relativamente maior em todos os níveis, apesar de os índices que são conhecidos nossos ainda permanecerem muito baixos. O segundo trata-se do aumento da escolarização em nível médio e superior de parcela relativa da população trabalhadora. $\mathrm{O}$ terceiro, por consequência do segundo aspecto, revela o direcionamento dos setores produtivos e econômicos na "redução no salário real dos formandos do ensino médio" (idem, ibidem) e o relativo "aumento do diferencial de salários para os formandos do ensino superior" (idem, ibidem). O quarto aspecto refere-se às chamadas "habilidades do século XXI" (idem, ibidem), que deveriam ser requisitos para o processo de aprendizagem profissional da "geração de trabalhadores no Brasil” (idem, ibidem). Esse último aspecto é explícito ao apresentar o roteiro dos requerimentos formativos para as competências e habilidades que os setores produtivos e econômicos vislumbram em seus receituários diários para as instituições públicas e privadas de formação profissional.

Nessa mesma direção socioeconômica e político-ideológica é que os fundamentos norteadores da política educacional, tanto para o ensino médio como para a educação profissional, cercados pelo processo social e econômico, não fogem aos ditames das orientações teórico-ideológicas hegemônicas. Desse modo, o circuito que agrega os fundamentos educacionais resulta em um discurso propositivo e relativamente crítico, mas, na disputa das forças internas e externas aos ditames da política nacional, acaba sendo suplantado pelo discurso hegemônico, fechando o circuito de orientações das políticas socioeconômicas e educacionais adotadas.

O trabalho também se constitui como prática econômica, obviamente porque nós garantimos nossa existência, produzindo riquezas e satisfazendo necessidades. Na sociedade moderna a relação econômica vai se tornando fundamento da profissionalização. Mas sob a perspectiva da integração entre trabalho, ciência e cultura, a profissionalização se opõe à simples formação para o mercado de trabalho. Antes, ela incorpora valores éticos-políticos e conteúdos históricos e científicos que caracterizam a práxis humana.

Portanto, formar profissionalmente não é preparar exclusivamente para o exercício do trabalho, mas é proporcionar a compreensão das dinâmicas socioprodutivas das sociedades modernas, com as suas conquistas e os seus revezes, e também habilitar as pessoas para o exercício autônomo e crítico de profissões, sem nunca se esgotar a elas. (Brasil, 2007b, p. 45)

O esforço do debate teórico-ideológico é pertinente, mas os entrelaçamentos dos ditames das políticas nacionais são decisivos para a realização dessas políticas e ficam fortalecidos nos aportes definidores, em especial ao afirmar corretamente 
que na "sociedade moderna a relação econômica vai se tornando fundamento da profissionalização" (idem, ibidem). Isso apenas confirma a funcionalidade da política educacional adotada no Brasil para a educação profissional ao atender os requerimentos educativos e profissionalizantes demandados pelos setores produtivos e econômicos nacionais, articulados aos interesses hegemônicos em âmbito internacional.

Esse processo reforça a direção conceitual e prática para a execução da política de educação profissional em todos os níveis e modalidades ofertadas, seja no universo do ensino médio ou não. A direção político-conceitual, ou seja, os motivos socioeconômicos e políticos e teórico-ideológicos e educacionais que sustentam o receituário das reformas realizadas no campo da educação, com destaque para a formação profissional, atua para sustentar um arcabouço ideológico e funcional que congrega elementos centrais visando demonstrar a mudança "da natureza do trabalho", o "valor do conhecimento como centralidade" e os "saberes e competências" (Brasil, 2012g, p. 910) requeridos para viver em circunstâncias de desemprego ou empregabilidade, de prontidão para alguma coisa que não se sabe ao certo o que será em termos reais e futuros. Nessa direção, registram-se os fundamentos da política de educação profissional:

Está ficando cada vez mais evidente que o que está mudando, efetivamente, é a própria natureza do trabalho. Está adquirindo importância cada vez mais capital o conhecimento científico e a incorporação de saberes em detrimento do emprego de massa, sem qualificação profissional e desempenho intelectual. O valor do Conbecimento passa a assumir significativa centralidade da nova organização da sociedade pós-industrial, onde o mundo se apresenta como mais instável e carregado de incertezas. Antigos postos de trabalho e emprego, bem como direitos trabalhistas consagrados, podem acabar desaparecendo rapidamente, abrindo perspectivas para a definição de novas políticas públicas para o trabalho, inclusive no campo da Educação Profissional e Tecnológica. Essas novas políticas públicas devem contemplar oferta mais flexível de cursos e programas objetivamente destinados à profissionalização dos trabalhadores de acordo com itinerários formativos que lhes possibilitem contínuo e articulado aproveitamento de estudos e de conhecimentos, saberes e competências profissionais constituídas. Neste contexto, a educação para a vida, em sentido lato, poderá propiciar aos trabalhadores o desenvolvimento de conhecimentos, saberes e competências que os habilitem efetivamente para analisar, questionar e entender os fatos do dia a dia com mais propriedade, dotando-os, também, de capacidade investigativa diante da vida, de forma mais criativa e crítica, tornando-os mais aptos para identificar necessidades e oportunidades de melhorias para si, suas famílias e a sociedade na qual vivem e atuam como cidadãos. (idem, ibidem, grifos do original)

Os fundamentos teórico-ideológicos que sustentam a política educacional brasileira, em particular os que definem a educação profissional, estão fortemente centrados em parâmetros que se podem caracterizar como hegemônicos, ao afirma- 
rem a funcionalidade e a racionalidade possível para as aprendizagens formativas e habilidades profissionalizantes. Isso porque estas estão ancoradas em um roteiro de competências nas quais a flexibilidade e a vulnerabilidade são internalizadas enquanto incertezas que devem ser tomadas como o eixo das respostas permanentes para a vida, para as aprendizagens e para a profissionalização. Assim, educar e profissionalizar para a racionalização econômica e política enquanto forma de buscar sustentabilidade na individualização dos processos acaba por forçar a crença nas incertezas como balizadoras do futuro:

O futuro do trabalho no mundo dependerá, em grande parte, do desenvolvimento da educação, desde que se consiga garantir sólida educação geral de base para todos e cada um dos seus cidadãos, associada a sólidos programas de Educação Profissional para seus jovens em processo formativo e seus adultos em busca de requalificação para o trabalho. Depende, também, fundamentalmente, do desenvolvimento da capacidade de aprender, para continuar aprendendo neste mundo em constante processo de mudanças. A descrição exata do futuro do trabalho, portanto, é a descrição de uma realidade nem de longe imaginada na virada do século e que será totalmente transformada daqui a outros dez anos ou mais [...]. Nesta nova realidade, é impossível para todos os cidadãos e em especial para os trabalhadores passar algum minuto sem aprender. Esse processo de aprendizagem permanente, inclusive na Educação Profissional e Tecnológica, deve contribuir efetivamente para a melhoria do mundo do trabalho, propiciando aos trabalhadores os necessários instrumentos para que possam romper com os mecanismos que os habilitam exclusivamente para a reprodução do status quo do capitalismo. (idem, p. 12, grifos do original)

O processo de individualização cria condições psicoideológicas que contribuem para explicar o processo de realização dos cursos e currículos das unidades educativas. Os fundamentos teórico-ideológicos e políticos são justificados apontando para a autonomia das instituições e dos indivíduos que nelas ingressam. No que tange às áreas formativas e de profissionalização, o processo de organização institucional, a escolha dos cursos e as decisões são identificadas como escolhas autônomas, criando a aparência da mobilidade socioeducativa e formativa.

Flexibilidade, interdisciplinaridade e contextualização ligam-se diretamente ao grau de autonomia conquistado pela escola na concepção, elaboração, execução e avaliação do seu projeto pedagógico, fruto e instrumento de trabalho do conjunto dos seus agentes educacionais, de modo especial dos seus docentes. Estes princípios refletem-se na construção dos currículos em diferentes perspectivas, o que abre um horizonte de liberdade e, em contrapartida, de maior responsabilidade para a instituição educacional. Ao elaborar o seu plano de curso, tem a incumbência de planejar os correspondentes itinerários formativos, por eixos tecnológicos, os quais são básicos para a construção dos respectivos currículos, estruturados em função dos almejados perfis profissionais de conclusão, conciliando as aspirações e demandas dos sujeitos e da sociedade. Esta incumbência 
confere à instituição educacional maior agilidade na proposição, atualização e incorporação de inovações, correções de rumos e adaptações às mudanças, o que implica em assumir responsabilidade de organização administrativa e pedagógica de forma efetivamente interdisciplinar. (idem, p. 48)

Esse processo, portanto, gera as condições para produzir um aparente e amplo significado social, com envergadura na dinâmica socioeconômica, possibilitando assim a funcionalidade formativa da força de trabalho necessária e a regulação do estoque disponivel, requeridos pelos setores econômicos nacionais e transnacionais. É por isso que,

De uma forma geral a educação profissional tem servido para preparar mão de obra (qualificação da força de trabalho) para as relações de produção capitalistas vigentes no Brasil. Predominou, ao longo da história, uma finalidade instrumental, operacional, qual seja, que o trabalhador fosse capaz de executar as funções que lhes são reservadas de forma mecânica e tecnicista. Esta função delegada ao então denominado ensino profissionalizante (ensino técnico) é resultado de uma sociedade estruturada de forma dual: proprietários dos meios de produção, detentores do capital e, trabalhadores, donos de sua força de trabalho a ser transformada em mercadoria de venda e produção. (Grabowski; Ribeiro, 2006, p. 2)

O aspecto socioeconômico fornece as condições para gerar o aspecto ideológico e nutrir o aspecto político. Estes acabam por se tornar hegemônicos, criando intencionalmente o vertedouro de sustentabilidade econômica, política e militar para a manutenção da estabilidade social da ordem estrutural vigente, na qual a educação ocupa funções ideológicas e pragmáticas destacadas no compósito das relações e mediações socioeconômicas e políticas na história brasileira.

Um financiamento ancorado em volumosos recursos financeiros que sustentaram a política educacional brasileira, com destaque para os destinados à formação profissional, no período de 2006 a 2011, revela a dimensão dos recursos públicos envolvidos, de um patamar de 1,5 bilhão de reais em 2006 para atingir quase 6 bilhões de reais em 2011 (Brasil, 2012e). Dados mais recentes, divulgados em 2013 em nota pública encaminhada ao Ministério da Educação (MEC) pelos pesquisadores reunidos no II Colóquio Nacional "A Produção do Conhecimento em Educação Profissional”, revelam que os valores previstos para a política de educação profissional "São 24 bilhões de reais (Brasil, 2012) cuja maior parte destina-se ao sistema ' $\mathrm{S}$ ', inclusive, para financiar a 'expansão da rede física de atendimento dos serviços nacionais de aprendizagem”' (IFRN, 2013, s.p.). Esses dados expressam a dimensão empírica e pragmática de um dos eixos funcionais sustentadores do escopo da política educacional brasileira, em particular a que define a formação profissional, como é o caso da estrutura de financiamento vigente.

Para complementar esta análise, precisamos refletir sobre os três principais aspectos que consideramos centrais na definição da política nacional de educação profissional e que disseminam os argumentos e as justificativas socioeconômicas e ideológicas às políticas adotadas. 
O primeiro aspecto é representado pela tendência hegemônica na definição das políticas educacionais nacionais de que há uma deficiência formativa da força de trabalho, gerando empecilhos ao desenvolvimento socioeconômico e desqualificando a competitividade nacional no campo da economia mundial. Essa tendência termina por reforçar os aspectos socioeconômicos pela via da disseminação ideológica, pois as ocupações de mais alta qualificação exigidas pelos setores produtivos demandam apenas $20 \%$ de pessoal altamente qualificado. Ou seja, os aspectos ideológicos sustentam mais a necessidade funcional e operativa do que as demandas socioeconômicas produtivas efetivamente estariam exigindo e requerendo em relação à formação profissional da força de trabalho brasileira.

O segundo aspecto é a tendência socioeconômica hegemônica a qual considera que o novo desenvolvimento econômico nacional precisa avançar em novos parâmetros de competitividade produtiva para sair de um suposto atraso tecnológico, educacional e produtivo. Esse aspecto, em certa medida, deixa de considerar que os setores produtivos, os postos de trabalho e a renda média salarial nacional, de um país que se destaca entre as dez economias mais ricas do mundo, vêm apresentando baixo rendimento salarial médio e diminuição de postos de trabalho em alguns setores estratégicos da base econômica nacional, pelo menos nos últimos vinte anos, sem, no entanto, diminuir a incorporação de tecnologias, equipamentos, produtividade e ganhos relativos crescentes.

O terceiro aspecto revela a tendência predominante na definição da política de educação profissional, que é a de avançar mais intencionalmente para reforçar os ditames educacionais e a viabilização financeira e ideológico-formativa das instituições privadas na realização e na oferta generalizada de educação profissional no Brasil.

Nesse contexto, as políticas adotadas para a educação profissional brasileira apresentam um cardápio de cursos e um receituário formativo registrado no catálogo nacional de cursos profissionalizantes ofertados pelas instituições públicas e privadas em todo o país. Constatamos, então, que nessas instituições predominam as ofertas de cursos profissionalizantes sem uma exigência mínima de escolarização, além dos cursos técnicos de nível médio como exigências formativas e ocupacionais demandadas pelos diversos setores produtivos e que estão vinculadas destacadamente ( $80 \%$ das ocupações) aos postos de baixa e média qualificação no universo dos setores produtivos nacionais.

\section{REFERÊNCIAS}

ANPEd - Associação Nacional de Pós-Graduação e Pesquisa em Educação. Por um Plano Nacional de Educação (2011-2020) como política de Estado. Presidente: Dalila Andrade Oliveira (UFMG). Comissão de Sistematização do Documento: Luiz Fernandes Dourado - Coordenadores: Antônio Cabral Neto, Carlos Roberto Jamil Cury, João Ferreira de Oliveira, José Marcelino Rezende Pinto, Lívia Maria Fraga Vieira, Maria Margarida Machado, Nilma Lino Gomes. Rio de Janeiro: ANPEd, 2011. 
Aquino, L. M. C. A juventude como foco das políticas públicas (Introdução). In: Castro, J. A.; Aquino, L. M. C.; Andrade, C. C. Juventude e politicas sociais no Brasil. Brasília: IPEA, 2009. p. 23-40.

Banco Mundial. Banco Internacional de Reconstrucción y Fomento. Educación técnica y formación profesional. Washington, DC: BM, 1992. (Primera edición en ingles: mayo de 1992; primera edición en español: abril de 1992).

O Estado num mundo em transformação. Relatório sobre o desenvolvimento mundial 1997. Washington, DC: BM, 1997.

Relatório anual do Banco Mundial 2009. (Ano em perspectiva). Washington, DC: BM, 2009.

Informe anual 2010. Reseña del ejercicio. Washington, DC: BIRF; BM, 2010a.

. Atingindo uma educação de nível mundial no Brasil: próximos passos. Sumário executivo. Washington, DC: BM, 2010b.

BID - Banco Interamericano de Desarrollo. Brasil. Estrategia del BID con Brasil 2012-2014. Washington, DC: BID, 2012.

. Estrategia para una política social favorable a la igualdad y la productividad. Sector social. Washington, DC: BID, s.d.

Brasil. Presidência da República. Casa Civil. Subchefia para Assuntos Jurídicos. Lei n. 9.394, de 20 de dezembro de 1996. Estabelece as diretrizes e bases da educação nacional. Diário Oficial da União, Brasília, DF, 23 dez. 1996.

. Anuário Estatístico do Brasil. Rio de Janeiro: IBGE, 2007a.

. Educaşão profissional técnica de nivel médio integrada ao ensino médio. Brasília, DF: MEC; SETEC, dez. 2007b.

. Anuário Estatístico do Brasil. Rio de Janeiro: IBGE, 2008.

Anuário Estatístico do Brasil. Rio de Janeiro: IBGE, 2009.

. Anuário Estatístico do Brasil. Rio de Janeiro: IBGE, 2010a.

. Secretaria Executiva Adjunta. CONAE 2010 - Conferência Nacional de Educação. Brasília, DF: CONAE, abr. 2010b.

. Ministério da Educação. Instituto Nacional de Estudos e Pesquisas Educacionais Anísio Teixeira. Resumo técnico - Censo Escolar 2010. Revisão 4 fev. 2011. Brasília, DF: INEP, 2011a.

. Ministério do Planejamento, Orçamento e Gestão. Instituto Brasileiro de Geografia e Estatística. Sinopse do Censo Demográfico 2010. Rio de Janeiro: IBGE, 2011b.

. Lei n. 12.513, de 26 de outubro de 2011. Institui o Programa Nacional de Acesso ao Ensino Técnico e Emprego (PRONATEC). Diário Oficial da União, Brasília, DF, 27 out. 2011c.

Diretoria de Políticas de Educação Profissional e Tecnológica. Catálogo Nacional dos Cursos Técnicos - Edição 2012. Brasília: MEC; SETEC, 2012a.

. Secretaria de Assuntos Estratégicos da Presidência da República. Instituto de Pesquisa Econômica Aplicada - IPEA. Políticas sociais: acompanhamento e análise, n. 20. Brasília, DF: IPEA, 2012b. 
. Programa Nacional de Acesso ao Ensino Técnico e Emprego - PRONATEC. Guia PRONATEC de cursos FIC. Brasília, DF: MEC; SETEC; PDE, 2012c.

PNAD 2011: Primeiras análises sobre o mercado de trabalho brasileiro. Comunicados do IPEA, n. 156, 11 out. 2012. Brasília: IPEA, 2012d. p. 14. Disponível em: <http://www.ipea.gov.br>. Acesso em: 10 dez. 2012.

. Subsecretaria de Planejamento e Orçamento - SPO. Relatório de Avaliação plano plurianual - 2008-2011. (Avaliação Setorial. Exercício 2012. Ano base 2011). Brasília, DF: MEC, 2012e. Disponível em: <www.mec.gov.br>. Acesso em: 10 dez. 2012.

. Sistema Nacional de Informações da Educação Profissional e Tecnológica - SISTEC. Brasília, DF: MEC; SISTEC, 2012f. Disponível em: <http://sitesistec.mec.gov.br/ index.php?option=com_content\&view=article\&id=255:resultado\&catid=42:resulta dos\&Itemid=217>. Acesso em: 25 fev. 2013.

Secretaria de Educação Profissional e Tecnológica. Conselho Nacional de Educação, Câmara de Educação Básica. Diretrizes curriculares nacionais para a educação profissional técnica de nível médio. (Aguardando homologação). Comissão: Adeum Hilário Sauer, Francisco Aparecido Cordão, José Fernandes de Lima, Mozart Neves Ramos. Processo n. 23001.000136/2010-95. Parecer CNE/CEB n. 11/2012. Brasília: MEC; SETEC; CNE; CEB, 2012g. Aprovado em: 9 maio 2012.

Bresser-Pereira, L. C. O Brasil e o novo desenvolvimentismo. Interesse nacional, abr.jjul. 2011. Disponível em: <http://www.bresserpereira.org.br/Papers/2011/10.26a. Brasil_Novodesenvolvimentismo_InteresseNacional.pdf>. Acesso em: 20 set. 2013.

Bryan, N. A. P. Educação, processo de trabalho, desenvolvimento econômico: contribuição ao estudo das origens e desenvolvimento da formação profissional no Brasil. Campinas: Alínea, 2008.

Castro, C. M. et al. Reforma de la educación primaria y secundaria en América Latina y el Caribe. Washington, DC: Banco Interamericano de Desarrollo, marzo-jun. 2000. (Serie de informes de políticas y estrategias sectoriales del Departamento de Desarrollo Sostenible).

Deitos, R. A. Ensino médio e profissional e seus vínculos com o BID/BRID: os motivos e as razões ideológicas da política educacional. Cascavel: EDUNIOESTE, 2000.

. A política educacional paranaense para o ensino médio e profissional (1995-2002): o PROEM e as recomendações do BID e Banco Mundial. In: Nogueira, F. M. G.; Rızzotтo, M. L. F. (Orgs.). Estado e políticas sociais: Brasil-Paraná. Cascavel: EDUNIOESTE, 2003. p. 101-118.

. O capital financeiro e a educação no Brasil. 2005.357f. Tese (Doutorado em Educação) - Faculdade de Educação, Universidade Estadual de Campinas, Campinas, 2005.

.História da política educacional paranaense para o ensino médio e profissional (1995-2002). Seminário Nacional de Estudos e Pesquisas "História, Sociedade E Educação no Brasil", 7., 2006, Campinas. In: 20 anos de HISTEDBR: navegando na história da educação brasileira. Campinas: UNICAMP; HISTEDBR, 2006. p. 194.

. Políticas públicas e educação: aspectos teórico-ideológicos e socioeconômicos. Acta Scientiarum. Education, Maringá: UEM, v. 32, n. 2, p. 209-218, 2010. 
.Estado, organismos internacionais e políticas sociais no Brasil. In: Chaves, M.; Setoguti, R. I.; Volsi, M.E. F. (Orgs.). A função social da escola: das políticas públicas às práticas pedagógicas. Maringá: EDUEM, 2011. p. 121-150.

. O liberalismo social-democrata e a reforma do Estado brasileiro (1995-2002). Perspectiva (UFSC), Florianópolis: UFSC, v. 30, p. 199-229, 2012.

.; LARA, A. M. B. Estado e política pública de educação profissional: os motivos socioeconômicos e políticos e as razões educacionais e teórico-ideológicas da política educacional paranaense. Imagens da Educação, Maringá: EDUEM, v. 2, n. 2, p. 75-86, 2012.

.; Zanardini, I. M.; Zanardini, J. B.; Figueiredo, I. M.Z. O PROEJA como política pública: aspectos socioeducacionais, políticos e institucionais. In: ZANARDINI, I. M. S.; Lima Filho, D. L.; Silva, M. R. (Orgs). Produção do conhecimento no PROEJA: cinco anos de pesquisa. 1. ed. Curitiba: Editora UTFPR, 2012. p. 65-102.

Dieese - Departamento Intersindical de Estatística e Estudos SocioecoNôMIcos. Qualificação e mercado de trabalho: apontamentos para política pública em regiões metropolitanas. Pesquisa DIEESE, São Paulo, n. 18, dez. 2011.

Fiep - Federação das Indústrias do Estado do Paraná. XVI Sondagem Industrial - 2011-2012. A visão dos líderes industriais paranaenses. Curitiba: FIEP; SEBRAE/ PR, 2011.

SESI. SENAI. IEL. Departamento Econômico. Indicadores conjunturais. Curitiba: FIEP, ano 27, n. 6, p. 14, jul. 2012. Disponível em: <http://www.fieppr.org. br/fiepr/analise/>. Acesso em: 20 nov. 2012.

Grabowski, G.; Ribeiro, J. A. R. Financiamento da educação profissional no Brasil: contradições e desafios. 2006. Disponível em: <http://portal.mec.gov.br/setec/arquivos/ pdf/conferencia_curriculo_gabriel.pdf >. Acesso em: 25 fev. 2013.

IFRN - Instituto Federal de Educação, Ciência e Tecnologia do Rio Grande do Norte. Programa de Pós-Graduação em Educação Profissional. Colóquio Nacional "A Produção do Conhecimento em Educação Profissional", 2., Rio Grande do Norte, 2013. Carta ao senhor ministro da Educação. Natal: IFRN, 2013. Disponível em: <http://www2.ifrn.edu.br/coloquioeducacao2013>. Acesso em: 15 out. 2013.

Marx, K. O capital: crítica da economia política. V. 1. Livro primeiro: o processo de produção do capital. Tomo I (Prefácios e Capítulos I a XII). Apresentação de Jacob Gorender. Coordenação e revisão de Paul Singer. Tradução de Regis Barbosa e Flávio R. Kothe. São Paulo: Abril Cultural, 1983.

Mercadante, A. O Brasil precisa aprender a fazer mais e melhor porque a crise exige mais educação. Brasil Econômico, Ideias em Destaque, São Paulo, 17 set. 2012, p. 4. Entrevista concedida a Octávio Costa e Simone Cavalcanti.

Mercadante-Oliva, A. As bases do novo desenvolvimentismo no Brasil: análise do Governo Lula (2003-2010). 2010.509f. Tese (Doutorado em Econonia) - Universidade Estadual de Campinas, Campinas, 2010.

Mészáros, I. Para além do capital: rumo a uma teoria da transição. Tradução de Paulo César Castanheira e Sérgio Lessa. São Paulo: Boitempo; Campinas: Editora da UNICAMP, 2002. 
Moreno, L. A. La década de América Latina y el Caribe: una oportunidad real. 2. ed. Washington, DC: Banco Interamericano de Desarrollo, 2011. (1. ed., mayo 2011; 2. ed. ampl., jul. 2011).

RoussefF, D. Dilma diz que não basta PIB crescer se vida do povo não melhorar. Notícias UOL. São Paulo: Reuters, 13 set. 2013, 12h09m, s.p. Disponível em: <www.uol.com.br>. Acesso em: 14 set. 2013.

Shiroma, E. O.; Lima Filho, D. L. Trabalho docente na educação profissional e tecnológica e no PROEJA. Educação E̋ Sociedade, Campinas: CEDES, v. 32, n. 116, p. 725-743, jul./set. 2011. Disponível em: <http://www.cedes.unicamp.br>. Acesso em: 29 jun. 2012.

Xavier, M. E. S. P. Capitalismo e escola no Brasil. A constituição do liberalismo em ideologia educacional e as reformas do ensino (1930-1961). Campinas: Papirus, 1990.

.; Deitos, R. A. Estado e política educacional no Brasil. In: Deitos, R. A.; Rodrigues, R.M.(Orgs.). Estado, desenvolvimento, democracia e politicas sociais. Cascavel: EDUNIOESTE, 2006. p. 67-86.

Zanardini, J. B. Ontologia e avaliação da educação básica no Brasil (1990-2007). 2008. 208f. Tese (Doutorado em Educação) - Universidade Federal de Santa Catarina, Florianópolis, 2008.

\section{SOBRE OS AUTORES}

Roberto Antonio Deitos é doutor em educação pela Universidade Estadual de Campinas (UNICAMP). Professor associado da Universidade Estadual do Oeste do Paraná (UNIOESTE).

E-mail: rdeitos@uol.com.br

Angela Mara de Barros Lara é doutora em educação pela Universidade Estadual Paulista (UNESP). Professora associada da Universidade Estadual de Maringá (UEM).

E-mail: angelalara@ymail.com

Recebido em março de 2014 Aprovado em outubro de 2014 